526 STELLA-2 TRIAL: SURGICAL COMPLICATIONS COMPARING EXTRAPERITONEAL VS TRANSPERITONEAL MIS AORTIC STAGING IN EARLY STAGE OVARIAN AND ENDOMETRIAL CANCER

IV Bebia Conesa*, 'A Gil-Moreno, 'S Cabrera, ${ }^{2}$ A Hernandez, ${ }^{3} \mathrm{~J}$ Gilabert-Estelles, ${ }^{4} \mathrm{M}$ Armengol Alsina, ${ }^{4} \mathrm{~PB}$ Asuncion, ${ }^{5} \mathrm{~B}$ Diaz-Feijoo. ${ }^{1}$ Hospital Universitari Vall d'Hebron, Gynecologic Oncology Unit, Barcelona, Spain; ${ }^{2}$ La Paz University Hospital, Gynecology Department, Madrid, Spain; ${ }^{3}$ Consorci Hospital General Universitari de València, Gynecology Department, València, Spain; ${ }^{4}$ Hospital Universitari Vall d'Hebron, Gynecologic Department, Barcelona, Spain; ${ }^{5}$ Hospital Clinic de Barcelona, Gynecologic Oncology Unit, Barcelona, Spain

\subsection{6/ijgc-2021-ESG0.164}

Introduction/Background* The surgical approach of minimally invasive surgery (MIS) for paraaortic staging lymphadenectomy (PALND) in gynecologic malignancies is controversial. The STELLA-2 trial was designed to determine whether the extraperitoneal approach for PALND results in a lower rate of surgical complications compared to the transperitoneal approach.

Methodology Prospective randomized multicenter study of patients with early-stage endometrial or ovarian cancer who underwent PALND as part of the staging process between June 2012 and January 2019. Patients were randomized to PALND by MIS (laparoscopy or robotic-assisted) using an extraperitoneal or a transperitoneal approach. The primary end point measure was a composite outcome that included developing one or more of the following surgical complications: bleeding during paraaortic lymphadenectomy $\geq 500$ $\mathrm{mL}$, any intraoperative complication related to paraaortic lymphadenectomy, severe postoperative complication (Dindo $\geq$ IIIA), impossibility to complete the procedure, or conversion to laparotomy. Secondary end points included the number of lymph nodes retrieved, the operative time, the length of hospital stay, and oncologic outcome (overall survival and diseasefree survival). A post-hoc analysis to compare all possible approaches (transperitoneal or extraperitoneal, robotic-assisted or laparoscopic) was performed.

ClinicalTrials gov id:NCT02676726).

Result(s)* Of 209 women randomized, 103 in the extraperitoneal group and 100 in the transperitoneal group underwent PALND. Differences in the composite outcome between both groups (transperitoneal $26.0 \%$ vs extraperitoneal $18.4 \%$ : $P=.195)$ were not found. A higher number of lymph nodes were retrieved through the extraperitoneal approached

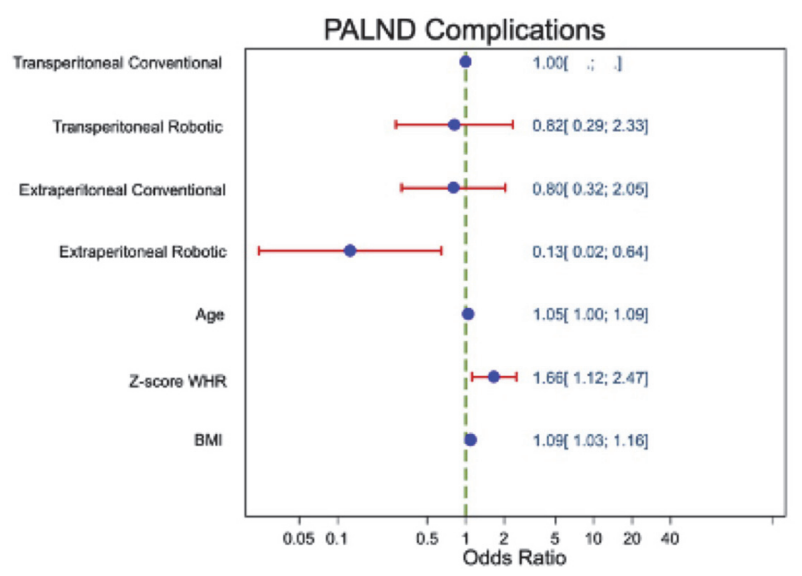

Abstract 526 Figure 1

(median, interquartile range [IQR] 12 [7-17] vs 14 [10-19]: $P=.026)$. Differences in the operative time, conversion to laparotomy, intraoperative bleeding, or survival were not observed.

The post-hoc multivariable analysis revealed that age (OR: 1.05, 95\% CI: 1.00-1.09), body mass index (OR: 1.09, 95\% CI: $1.03-1.16$ ), and waist-hip ratio (OR: 1.66, 95\% CI: $1.12-$ 2.47) were found to independently increase the risk of PALND complications, while extraperitoneal robotic approach (OR: 0.13 , 95\% CI 0.02-0.64) was an independent protective factor for complication occurrence.

Conclusion* Extraperitoneal approach is a safe procedure for PALND in the minimally invasive surgical staging of women diagnosed with early-stage endometrial or ovarian malignancy. Moreover, in the post-hoc analysis, robotic-assisted extraperitoneal PALND was associated with fewer surgical complications.

\section{LAPAROSCOPICAL SENTINEL NODE FOR LOW AND INTERMEDIATE RISK ENDOMETRIAL CANCER: PILOT RESULTS OF A PROSPECTIVE COHORT}

S Petousis*, A Daniilidis, C Margioula-Siarkou, A Liberis, A Papanikolaou, K Dinas. Aristotle University of Thessaloniki, 2nd Department of Obstetrics and Gynaecology, Thessaloniki, Greece

10.1136/ijgc-2021-ESGO.165

Abstract 526 Table 1 Intraoperative, early, and late complications associated with paraaortic lymph node dissection (PALND)

\begin{tabular}{|c|c|c|c|}
\hline \multirow[b]{2}{*}{ Complication } & \multicolumn{2}{|c|}{ Laparoscopic approach } & \multirow{2}{*}{$\begin{array}{c}P \\
\text { Value }\end{array}$} \\
\hline & $\begin{array}{l}\text { Extraperitoneal } \\
\qquad(\mathrm{N}=103)\end{array}$ & $\begin{array}{c}\text { Transperitoneal } \\
(\mathrm{N}=100)\end{array}$ & \\
\hline Intraoperative, N (\%) & $2(1.9)$ & $7(7.0)$ & .642 \\
\hline Vascular injury & $2(1.9)$ & $3(3.0)$ & \\
\hline Inferior mesenteric artery & & 1 & \\
\hline Vena cava & 2 & 1 & \\
\hline Left renal vein & & 1 & \\
\hline Intestinal serosal lesion & & $2(2.0)$ & \\
\hline Ureteral lesion & & $2(2.0)$ & \\
\hline Incomplete PALND, N (\%) & $9(8.7)$ & $13(13.0)$ & .330 \\
\hline Conversion to transperitoneal approach, $\mathrm{N}(\%)$ & $8(7.8)$ & NA & \\
\hline Conversion to laparotomy, $\mathrm{N}(\%)$ & $9(8.7)$ & $6(6.0)$ & .456 \\
\hline Early postoperative ( $\leq 30$ days), $\mathrm{N}(\%)$ & $1(1.0)$ & $1(1.0)$ & 1.00 \\
\hline Chylous ascites (Dindo $\geq$ IIIA) & $1(1.0)$ & $1(1.0)$ & \\
\hline Late postoperative (> 30 days until 6 months), $\mathrm{N}(\%)$ & $2(1.9)$ & 0 & .506 \\
\hline Lymphedema left lower limb & $2(1.9)$ & & \\
\hline
\end{tabular}

